\title{
APLIKASI TINGKAT KEPUASAN MAHASISWA TERHADAP LAYANAN ADMINISTRASI FAKULTAS TEKNIK UNIVERSITAS MUHAMMADIYAH BENGKULU
}

\author{
Andilala $^{1}$, Marhalim $^{2}$ \\ ${ }^{1}$ Program Studi Sistem Informasi, Fakultas Teknik Universitas Muhammadiyah Bengkulu \\ ${ }^{2}$ Program Studi Teknik Informatika, Fakultas Teknik Universitas Muhammadiyah Bengkulu \\ Jl. Bali PO BOX 118. Telp (0736) 227665, Fax (0736) 26161, Bengkulu 38119 \\ ${ }^{1}$ andilala@umb.ac.id \\ ${ }^{2}$ marhalimeumb.ac.id
}

Abstrak - Penelitian ini bertujuan untuk membuat aplikasi yang dapat dijadikan tolak ukur dalam tatakelola institusi terutama tatakelola fakultas teknik dalam hal melakukan pelayanan terhadap mahasiswa, subjek dalam penelitian ini adalah mahasiswa aktif fakultas teknik yang terdiri dari program studi informatika dan program studi sistem informasi. Dengan adanya penelitian ini diharapkan stakeholder yang ada di fakultas teknik menyadari betapa pentingnya mengutamakan pelayanan terhadap mahasiswa sebab keberhasilan suatu fakultas khususnya program studi sebagai unit kerja pada perguruan tinggi salah satunya ditentukan oleh mutu pelayanan yang diberikan kepada mahasiswa. Untuk mengetahui mutu pelayanan yang diberikan kepada mahasiswa adalah dengan cara melakukan evaluasi, salah satu cara evaluasi yang dapat dilakukan adalah dengan melakukan pengukuran tingkat kepuasan mahasiswa terhadap layanan yang di berikan oleh fakultas terutama oleh program studi dan tata usaha.

Kata Kunci : Penelitian, Aplikasi, Informasi, IKM.

\begin{abstract}
This study aims to create applications that can be used as benchmarks in institutional governance, especially in the management of engineering faculties in terms of providing services to students, the subjects in this study are active students of engineering faculty consisting of informatics study programs and information systems study programs.
\end{abstract}

With this research it is expected that stakeholders in the engineering faculty realize how important it is to prioritize services to students because the success of a faculty, especially study programs as work units in tertiary institutions, one of which is determined by the quality of services provided to students.

To find out the quality of services provided to students is to do an evaluation, one of the evaluations that can be done is to measure the level of student satisfaction with the services provided by the faculty, especially by study programs and administration.

Key word: research, Aplikation, Information, IKM.

\section{PENDAHULUAN}

Persaingan antar perguruan tinggi untuk menarik calon mahasiwa dewasa ini sangat tinggi, hal ini dapat dilihat dari gencarnya suatu perguruan tinggi melakukan promosi baik itu dimedia cetak maupun pada media elektronik, persaingan yang cukup kompetitif antar perguruan tinggi memaksa suatu perguruan tinggi untuk menjaga dan menjamin mutu dan kualitas kelembagaan agar dapat bertahan dan unggul dari perguruan tinggi lainnya.

Jaminan mutu dan kualitas kelembagaan tersebut sejalan dengan tingginya kesadaran masyarakat akan nilai perguruan tinggi mengakibatkan peningkatan tuntutan dari masyarakat terhadap kualitas dan mutu perguruan tinggi. Menurut Badan Akreditasi 
Jurnal Pseudocode, Volume VI Nomor 2, September 2019, ISSN 2355-5920, e-ISSN 2655-1845 www.ejournal.unib.ac.id/index.php/pseudocode

Nasional Perguruan Tinggi (BAN-PT), tuntutan masyarakat kepada perguruan tinggi meliputi jaminan kualitas (quality assurance), pengendalian kualitas (quality control), dan perbaikan kualitas (quality improvement). Upaya menerapkan tuntutan masyarakat terhadap kualitas pendidikan perguruan tinggi ini diPelayanani BAN-PT dengan program akreditasi berkala bagi universitas negeri dan swasta di Indonesia [1].

Jaminan mutu dan kualitas kelembagaan perguruan tinggi dapat dilihat melalui tingkat kepuasan mahasiswa selama menjalani proses perkuliahan, dimana pelayanan akademik yang berkualitas dapat diidentifikasi melalui kepuasan mahasiswa. Untuk mencapai tingkat kepuasan yang tinggi, diperlukan adanya pemahaman tentang apa yang diinginkan oleh konsumen yang ada dalam lembaga untuk memenuhi kebutuhan konsumen yang bersangkutan [2].

Hal ini mengindikasikan bahwa kepuasaan konsumen dalam hal ini mahasiswa berawal dari pemahaman tentang apa yang diinginkan oleh mahasiswa. Salah satu hal yang sangat diperlukan oleh mahasiswa adalah pelayanan yang baik, mulai dari proses registrasi, perkuliahan, ujian sampai dengan mahasiswa menyelesaikan kuliah. Untuk menunjang hal tersebut, diperlukan perencanaan yang matang, fasilitas yang memadai, dan sumber daya manusia yang mendukung.

Untuk mengetahui apa yang diinginkan oleh mahasiswa terutama dalam hal pelayanan adalah dengan cara mengukur tingkat kepuasan, hasil dari pengukuran tingkat kepuasan ini dapat digunakan untuk mengetahui kelebihan dan kekurangan dari masing-masing unit pelayanan.
Fakultas Teknik Universitas Muhammadiyah Bengkulu sebagai lembaga penyedia layanan pendidikan tinggi, dituntut untuk senantiasa mengutamakan kepuasan mahasiswa sebagai pelangan dengan cara selalu memberikan layanan yang terbaik.

Fakulas Teknik Universitas Muhammadiyah Bengkulu telah beberapa kali melakukan pengukuran tingkat kepuasan mahasiswa tetapi hanya sebatas pengukuran kepuasan mahasiswa terhadap dosen mengajar saja, dan pengolahan datanyapun dilakukan secara manual dengan menggunakan Microsoft Excel. Sedangkan pelayanan yang ada pada fakultas teknik terdapat beberapa bidang pelayanan seperti layanan Program studi Informatika, Layanan Program Studi Sistem Informasi dan Layanan Tata Usaha, pelayanan akademik yang baik akan dapat membentuk citra positif bagi Universitas Muhammadiyah Bengkulu Khususnya Fakultas Teknik sebagai fakulas penyedia layanan.

Pada aktifitas layanan akademik yang dilakukan tersebut terdapat kemungkinan ketidakpuasan mahasiswa terhadap layanan yang diangap kurang optimal sehingga perlu dilakukan penelitian pengukuran tingkat kepuasan untuk mengetahui kualitas layanan yang diberikan. oleh sebab itu pada penelitian ini dikembangkan pengukuran tingkat kepuasan mahasiswa terhadap layanan akademik yang ada pada fakultas teknik dengan pengukurannya menggunakan aplikasi yang khusus menangani dan mengolah data tentang kepuasan mahasiswa.

\section{LANDASAN TEORI}

\subsection{Penelitian Terkait}

Penelitian yang dilakukan oleh [3] pada Politeknik Negeri Bali dengan membangun 

www.ejournal.unib.ac.id/index.php/pseudocode

sistem informasi pengukuran tingkat kepuasan mahasiswa dengan metode servqual. Penelitian ini bertujuan untuk menerapkan metode servqual dan skala likert pada sistem informasi yang mereka bangun. Analisis tentang tingkat kepuasan mahasiswa terhadap kinerja dosen, pada penelitian ini dilakukan untuk mengetahui tangapan mahasiswa atas kinerja dosen unisma dan untuk mengetahui faktor-faktor pelayanan yang mempengaruhi kepuasan atau ketidakpuasan mahasiswa unisma [4].

Penelitian tentang persepsi mahasiswa terhadap pelayanan administrasi pegawai biro administrasi akademik dan kemahasiswaan (baak) di universitas negeri padang, penelitian ini dilakukan untuk mengetahui kepuasan mahasiswa terhadap layanan BAAK pada Universitas Negeri Padang [5].

Peraturan Menteri Pendayagunaan Aparatur Negara dan Birokrasi No. 14 Tahun 2017 tentang Pedoman Survei Indeks Kepuasan Masyarakat. Pada peraturan ini dijelaskan tentang bagaimana tahapan-tahapan yang harus dilakukan dalam melakukan pengukuran indeks kepuasan masyarakat terhadap layanan publik yang mencakup sembilan unsur [6].

\subsection{Konsep Kepuasan Mahasiswa}

Setelah mahasiswa mengikuti kuliah, mahasiswa akan merasakan tingkat kepuasan atau tingkat ketidakpuasan tertentu. Kepuasan adalah tingkat perasaan seseorang setelah membuat perbandingan antara kenyataan yang ia rasakan dengan harapannya. Menurut [7], Mahasiswa dapat mengalami salah satu dari tingkat kepuasan yang umum yaitu: (1) Jika kinerja di bawah harapan, mahasiswa akan tidak puas, (2) kalau kinerja sesuai dengan harapan, mahasiswa akan puas, (3) apabila kinerja melampaui harapan, mahasiswa akan merasa sangat puas, senang, atau bahagia. Perasaan tidak puas, puas atau sangat puas ini akan mempengaruhi tindakan selanjutnya.

Mahasiswa yang merasa puas akan menyampaikan secara positif tentang jasa yang dia gunakan/konsumsi. Mahasiswa yang tidak puas akan bereaksi secara berlainan. Mahasiswa yang tidak puas akan mengambil satu dari dua tindakan berikut ini: (1) mereka mungkin berusaha mengurangi ketidakpuasan tersebut dengan meninggalkan atau pindah ke program studi lain atau ke perguruan tinggi lain. (2) mereka mungkin berusaha mengurangi ketidakpuasan dengan mencari informasi yang dapat memperkuat nilai tinggi jasa tersebut (menghindari informasi yang mungkin memperkuat nilai rendahnya). Pimpinan/manajemen dapat mengambil langkah untuk meminimalkan jumlah ketidakpuasan mahasiswa, misalnya dengan mengadakan komunikasi secara periodik. Komunikasi dengan para mahasiswa dapat dilakukan dengan menyediakan forum komunikasi yang baik bagi keluhan mahasiswa dan menangani keluhan tersebut dengan cepat.

Harapan mahasiswa dibentuk oleh komentar teman dan kenalannya, serta informasi dan janji lembaga, dan pesaingnya. Apabila lembaga menaikkan harapan mahasiswa terlalu tinggi, mahasiswa mungkin akan kecewa jika lembaga gagal dalam memenuhinya. Di lain pihak, jika lembaga menetapkan harapan mahasiswa terlalu rendah, maka lembaga tidak dapat menarik cukup banyak calon mahasiswa meskipun mahasiswa akan puas. Tingkat kepuasan atau 

www.ejournal.unib.ac.id/index.php/pseudocode

kesenangan yang tinggi akan menciptakan ikatan emosional yang tinggi. Lembaga perlu membentuk budayanya sedemikian rupa sehingga orang dalam lembaga bertujuan menyenangkan mahasiswa.

\section{METODE PENELITIAN}

\section{A. Metode Penelitian}

Dalam melakukan penelitian ini, menggunakan metode pengembangan sistem yang mana tahapan dalam pengembangan sistem ini terdiri dari enam tahapan yaitu:

a. Survey, bertujuan mengetahui ruang lingkup pekerjaan.

b. Analisis, bertujuan untuk memahami sistem yang ada mengidentifikasi masalah dan solusinya.

c. Desain, bertujuan untuk mendesain sistem yang baru yang dapat mempermudah atau menyelesaikan masalah yang ada.

d. Kode bertujuan untuk membuatkan sistem yang dibutuhkan

e. Testing dan Implementasi yang bertujuan untuk mencoba dan mengimplementasikan sistem yang baru.

B. Metode Pengumpulan Data

Adapun metode pengumpulan data yang digunakan dalam penelitian ini adalah sebagai berikut:

a. Studi pustaka (Library Research)

Metode ini dilakukan dengan cara mengadakan peninjauan terhadap buku-buku, referensi, dan sumber-sumber data yang lainnya yang berhubungan dengan masalah yang diteliti, yaitu sistem informasi penelusuran Penelitian berbasis web yang mendapatkan landasan teori dalam penelitian yang bisa dijadikan pedoman dalam menarik suatu kesimpulan.

b. Studi lapangan (Field Research) Metode ini dilakukan dengan cara mengadakan hubungan langsung terhadap objek yang diteliti, adapun cara yang yang dilakukan sebagai berikut:

1. Wawancara, yaitu mengumpulkan data dengan cara tanya jawab kepada penjaga perpustakaan dan mahasiswa yang sedang melakukan pencarian Penelitian sebagai bahan referensi

2. Observasi, mengadakan pengamatan langsung kegiatan pada perpustakaan.

\section{Analisa Sistem Lama}

Sebelum melakukan perancangan dan pembuatan Aplikasi, terlebih dahulu penulis menganalisis tentang pengukuran tingkat kepuasan mahasiswa terhadap layanan administrasi yang telah dilakukan oleh tingkat fakultas, ternyata setelah dianalisa survei tentang pengukuran tingkat kepuasan mahasiswa terhadap layanan administrasi akademik di tingkat fakultas belum pernah dilakukan, yang pernah dilakukan adalah survei tentang kinerja dosen dalam mengajar dan itupun pengolahan datanya masih manual sehingga untuk mengetahui hasilnya membutuhkan waktu yang cukup lama.

\section{Analisa Sistem Baru}

Dalam penelitian ini penulis akan merancang dan membuat suatu Aplikasi sebagai media yang digunakan untuk melakukan pengukuran tingkat kepuasan mahasiswa terhadap layanan administrasi fakultas teknik Universitas Muhammadiyah Bengkulu yang diharapkan dapat membantu dan mempermudah untuk 
Jurnal Pseudocode, Volume VI Nomor 2, September 2019, ISSN 2355-5920, e-ISSN 2655-1845 www.ejournal.unib.ac.id/index.php/pseudocode

mengetahui tingkat kepuasan mahasiswa terhadap layanan administrasi.

Metodologi pengembangan sistem perangkat lunak (atau disebut juga model proses atau paradigma rekayasa perangkat lunak) adalah suatu strategi pengembangan yang memadukan proses, metode, dan perangkat (tools). Metode rekayasa perangkat lunak, memberikan teknik untuk membangun perangkat lunak.

Berikut ini merupakan Metode yang penulis pergunakan dalam penelitian ini yaitu metode Incremental.

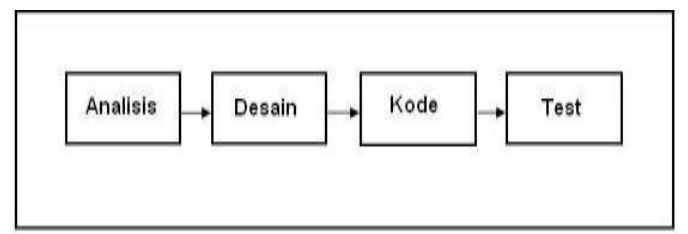

Gambar 1. Tahapan Metode Incremental

E. Roadmap Penelitian

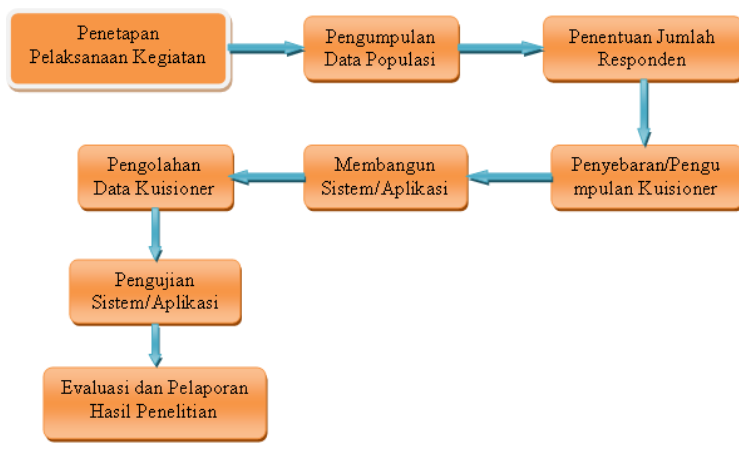

Gambar 2. Roadmap penelitian

\section{HASIL DAN PEMBAHASAN}

4.1. Hasil

A. Pengumpulan data dan populasi

Berdasarkan jumlah populasi mahasiswa yang ada difakultas teknik tahun 2019 sebanyak 1119 orang mahasiswa.

B. Penentuan Jumlah Responden

Merujuk pada Peraturan Menteri Pendayagunaan Aparratur Negara dan Reformasi Birokrasi
Nomor 17 Tahun 2017 Tentang Pedoman

Penyususnan Survei Kepuasan Masyarakat unit Penyelenggara Pelayanan Publik yang didalamnya memuat tentang aturan penarikan sampel morgan dan krejcie maka responden yang dijadikan sampel pada penelitian ini adalah sebanyak 291 orang responden.

Tabel 1 Morgan dan Krejie

\begin{tabular}{|c|c|c|c|c|c|}
\hline $\begin{array}{c}\text { Populasi } \\
\text { (N) }\end{array}$ & $\begin{array}{c}\text { Sampel } \\
\text { (n) }\end{array}$ & $\begin{array}{c}\text { Populasi } \\
\text { (N) }\end{array}$ & $\begin{array}{l}\text { Sampel } \\
\text { (n) }\end{array}$ & $\begin{array}{c}\text { Populasi } \\
\text { (N) }\end{array}$ & $\begin{array}{c}\text { Sampel } \\
\text { (n) }\end{array}$ \\
\hline 10 & 10 & 220 & 140 & 1200 & 291 \\
\hline 15 & 14 & 230 & 144 & 1300 & 297 \\
\hline 20 & 19 & 240 & 148 & 1400 & 302 \\
\hline 25 & 24 & 250 & 152 & 1500 & 306 \\
\hline 30 & 28 & 260 & 155 & 1600 & 310 \\
\hline 35 & 32 & 270 & 159 & 1700 & 313 \\
\hline 40 & 36 & 280 & 162 & 1800 & 317 \\
\hline 45 & 40 & 290 & 165 & 1900 & 320 \\
\hline 50 & 44 & 300 & 169 & 2000 & 322 \\
\hline 55 & 48 & 320 & 175 & 2200 & 327 \\
\hline 60 & 52 & 340 & 181 & 2400 & 331 \\
\hline 65 & 56 & 360 & 186 & 2600 & 335 \\
\hline 70 & 59 & 380 & 191 & 2800 & 338 \\
\hline 75 & 63 & 400 & 196 & 3000 & 341 \\
\hline 80 & 66 & 420 & 201 & 3500 & 346 \\
\hline 85 & 70 & 440 & 205 & 4000 & 351 \\
\hline 90 & 73 & 460 & 210 & 4500 & 354 \\
\hline 95 & 76 & 480 & 214 & 5000 & 357 \\
\hline 100 & 80 & 500 & 217 & 6000 & 361 \\
\hline 110 & 86 & 550 & 226 & 7000 & 364 \\
\hline 120 & 92 & 600 & 234 & 8000 & 367 \\
\hline
\end{tabular}

\section{Penyebaran Quisioner}

Penyebaran dan pengisian kuisioner melibatkan 8 orang mahasiswa yang kami sebut sebagai tenaga pembantu lapangan, ada 2 cara yang dilakukan oleh petugas pembantu lapangan dalam pengisian quisioner, pertama petugas lapangan melihat jadwal perkuliahan, ruangan mana saja yang sedang melakukan perkuliahan lalu petugas memiinta izin kepada dosen yang mengajar untuk melakukan survei kepada mahasiswa agar mengisi quisioner yang diberikan. Kedua petugas lapangan mendatangi mahasiswa yang ada di luar ruangan satu persatu 
Jurnal Pseudocode, Volume VI Nomor 2, September 2019, ISSN 2355-5920, e-ISSN 2655-1845 www.ejournal.unib.ac.id/index.php/pseudocode

untuk meminta kepada mahasiswa tersebut mengisi quisioner yang telah disiapkan.

D. Membangun Aplikasi

1. Menu Login Admin

Pada tampilan ini admin login terlebih dahulu sebelum admin melakukan proses pengolahan data. Adapun bentuk tampilan dapat dilihat pada gambar di bawah ini:

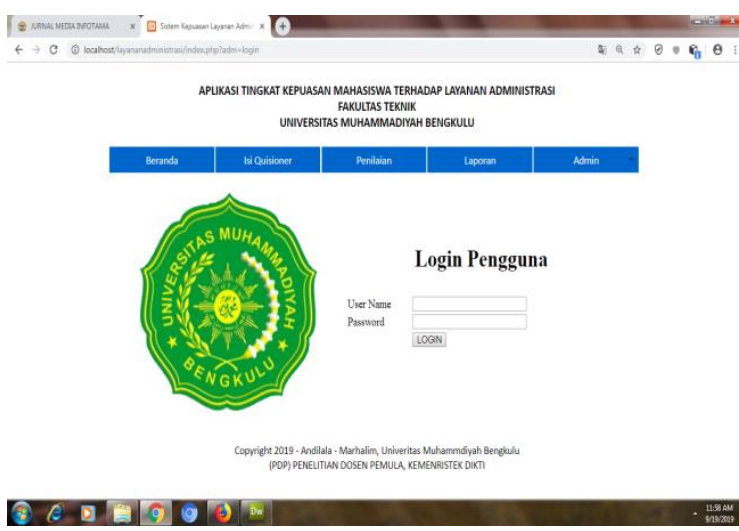

Gambar 3. Tampilan Beranda Admin

Pada tampilan ini admin mempunyai hak untuk mengolah data:
a. Beranda
b. Isi Quisioner
c. Penilaian
d. Laporan
e. Admin

adapun bentuk tampilan beranda admin dapat dilihat pada gambar di bawah ini:

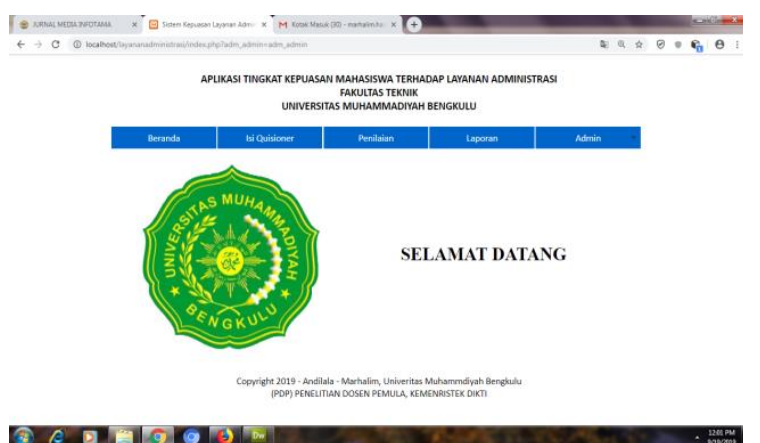

Gambar 4. Tampilan Beranda Admin

\section{Menu Isi Quisioner}

Menuisi quisioner ini diisi oleh responden ataupun responden yang merupakan mahasiswa aktif fakultas teknik Universitas Muhammadiyah Bengkulu Bentuk Quisioner bisa dilihat pada gambar di bawah ini:

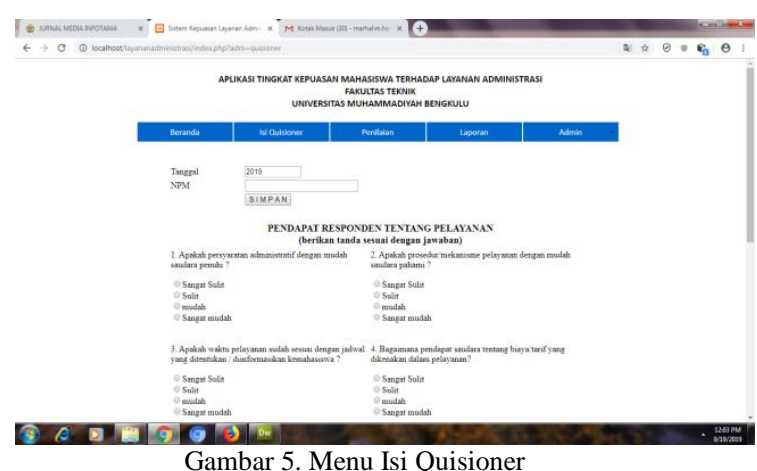

3. Menu Penilaian

Pada menu penilaian ini, admin memilih tahun yang dijadikan acuan penilaian selanjutnya admin memilih dan mengklik tombol hitung adapun tampilan pada menu penilaian ini dapat dilihat pada gambar di bawah ini:

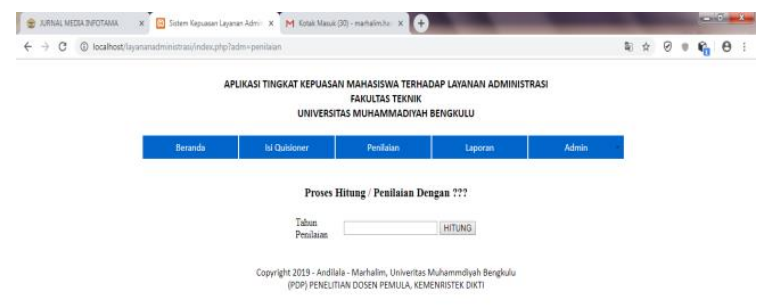

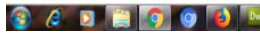

Gambar 6. Menu Penilaian

4. Menu Laporan

Pada menu laporan ini dapat dilihat jumlah responden yang telah mengisi quisioner, adapun 

www.ejournal.unib.ac.id/index.php/pseudocode

tampilan pada menu laporan ini dapat dilihat pada gambar di bawah ini:

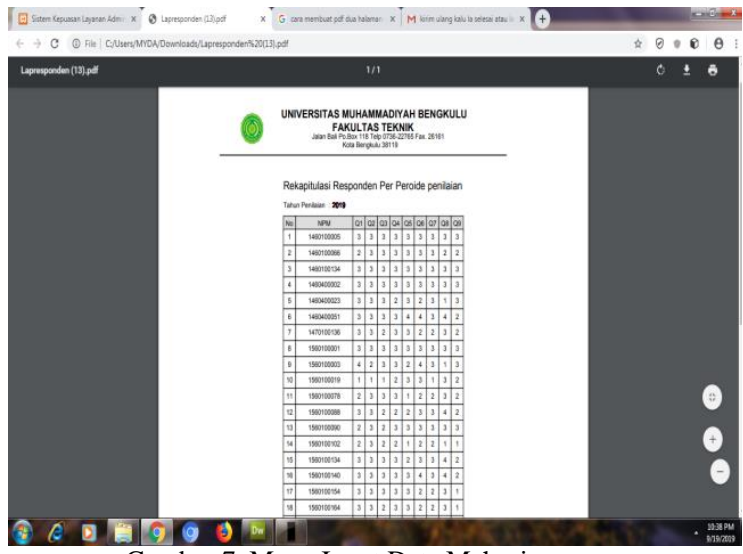

Gambar 7. Menu Input Data Mahasiswa

\subsection{Pembahasan}

Analisis yang dilakukan pada hasil survei IKM terhadap pelayanan Publik di Pelayanan administrasi fakultas teknik pada tahun 2019 ini antara lain untuk mengetahui tingkat kepuasan mahasiswa fakultas teknik dengan tujuan untuk dapat mengetahui dan memprioritaskan pembenahan terhadap pelayanan kepada mahasiswa.

Berdasarkan hasil survey IKM terhadap pelayanan yang telah dilakukan, selanjutnya diperoleh indikator kepuasan mahasiswa yang meliputi nilai rata-rata kepuasan terhadap pelayanan yang dirasakan oleh mahasiswa, nilai IKM tiap unsur dan mutu pelayanan dari masingmasing unsur dapat dilihat pada tabel di bawah ini:

Tabel 2. Nilai kuesioner per unsur pelayanan

\begin{tabular}{c|l|c|c|c|l}
\hline No. & UNSUR PELAYANAN & $\begin{array}{c}\text { Nilai Rata- } \\
\text { rata }\end{array}$ & $\begin{array}{c}\text { Nilai } \\
\text { IKM/Unsur }\end{array}$ & $\begin{array}{c}\text { Mutu } \\
\text { Pelayanan }\end{array}$ & Keterangan \\
\hline Q1 & Persyaratan & 3,052 & 76,29 & C & KURANG BAIK \\
\hline Q2 & Sistem, Mekanisme, dan prosedur & 3,089 & 77,23 & B & BAIK \\
\hline Q3 & Waktu penyelesaian & 2,918 & 72,94 & C & KURANG BAIK \\
\hline Q4 & Biaya/Tarif & 3,344 & 83,59 & B & BAIK \\
\hline Q5 & Produk Spesifikasi jenis pelayanan & 3,148 & 78,69 & B & BAIK \\
\hline Q6 & Kompetensi pelaksana & 3,155 & 78,87 & B & BAIK \\
\hline Q7 & Perlaku pelaksana & 2,928 & 73,20 & C & KURANG BAIK \\
\hline Q8 & Penanganan pengaduan, saran dan masukkan & 3,210 & 80,24 & B & BAIK \\
\hline Q9 & Sarana dan prasarana & 3,093 & 77,32 & B & BAIK \\
\hline
\end{tabular}

Tabel di atas menunjukkan bahwa secara umum, mahasiswa yang meraskan pelayanan di fakultas teknik merasa Puas atau kinerja pelayanan yang diberikan Sedang atau baik, hal ini dapat dilihat berdasarkan dari nilai masingmasing unsur yang didominasi oleh nilai B (Baik) sebanyak 6 unsur dan 3 unsur pelayanan yang mendapatkan nilai C (kurang baik).

Berikut ini merupakan penjelasan tiap unsur dari hasil Survey IKM di Pelayanan administrasi fakultas teknik:

1. Unsur Persyaratan (Q1)

Pada tabel Tingkat kepuasan mahasiswa dari masing-masing unsur menunjukan nilai rata

- rata performance untuk unsur persyaratan sebesar 3,052 dan nilai IKM sebesar 76,29 Kurang Baik (C). Persyaratan pelayanan di pelayanan administrasi fakultas teknik dirasa Kurang Sesuai dan responden merasa Kurang puas.

2. Unsur Sistem, Mekanisme, dan prosedur (Q2)

Prosedur pada tabel Tingkat kepuasan mahasiswa dari masing-masing unsur menunjukan nilai rata - rata performance untuk unsur prosedur sebesar 3,089 dan nilai IKM 77,23 Baik (B).

3. Unsur Waktu penyelesaian (Q3)

Pada tabel Tingkat kepuasan mahasiswa dari masing-masing unsur menunjukan menunjukan nilai rata - rata performance untuk unsur waktu pelayanan sebesar 2,918 dan nilai IKM 72,94 Kurang Baik (C).

4. Unsur Biaya/Tarif (Q4)

Nilai rata - rata performance untuk unsur Biaya atau tarif pelayanan sebesar 3,344 dan nilai IKM 83,59 Baik (B). 
Jurnal Pseudocode, Volume VI Nomor 2, September 2019, ISSN 2355-5920, e-ISSN 2655-1845 www.ejournal.unib.ac.id/index.php/pseudocode

5. Unsur Produk Spesifikasi jenis pelayanan (Q5)

Pada tabel Tingkat kepuasan mahasiswa dari masing-masing unsur menunjukan nilai rata

- rata performance untuk unsur Produk Spesifikasi jenis Pelayanan sebesar 3,148 dan dengan inilai IKM sbesar 78,69 Baik (B).

6. Unsur Kompetensi pelaksana (Q6)

Pada unsur Kompetensi pelaksana menunjukan nilai rata - rata performance untuk unsur Kompetensi Pelayanan sebesar 3,155 dan dengan nilai IKM sebesar $\mathbf{7 8 , 8 7}$ Baik (B).

7. Unsur Perilaku pelaksana (Q7)

Pada unsur perilaku pelaksana menunjukan nilai rata - rata performance untuk unsur Perilaku Pelaksana dalam memberikan Pelayanan sebesar 2,928 dan dengan inilai IKM sebesar 73,20 Kurang Baik (C).

8. Unsur Penanganan pengaduan, saran dan masukkan (Q8)

Pada tabel Tingkat kepuasan mahasiswa dari masing-masing unsur menunjukan nilai rata - rata performance untuk unsur Penanganan Pengaduan, Saran dan Masukan sebesar 3,210 dan inilai IKM sebesar 80,24 Baik (B).

9. Unsur Sarana dan prasarana (Q9)

Pada tabel Tingkat kepuasan mahasiswa dari masing-masing unsur menunjukan nilai rata

- rata performance untuk sarana dan prasarana sebesar 3,093 dan inilai IKM sebesar 77,32 dengan nilai kinerja Baik (B).

Hasil Dari Pengolahan Data Kuisioner Yang Diisi Oleh Responden Didapatkan Nilai IKM Dari Pelayanan administrasi akademik Fakultas Teknik Universitas Muhammadiyah Bengkulu adalah sebesar $\mathbf{7 6 , 8 2}$ dengan Nilai kinerja pelayanan Baik (B) seperti yang tertera pada gambar di bawah ini :

\section{IKM UNIT PELAYANAN : $\quad \mathbf{7 6 , 8 2}$}

\section{Mutu Pelayanan :}

$\begin{array}{ll}\text { A (Sangat Baik) } & : 88,31-100,00 \\ \text { B (Baik) } & : 76,61-88,30 \\ \text { C (Kurang Baik) } & : 65,00-76,60 \\ \text { D (Tidak Baik) } & : 25,00-64,99\end{array}$

Gambar 8. Nilai IKM Fakultas Teknik

\section{KESIMPULAN DAN SARAN}

A. Kesimpulan

Kesimpulan yang dapat ditarik dari sistem penilaian kepuasan pelayan Administrasi Fakultas Teknik adalah sebagai berikut :

1. Dapat diketahui indeks kepuasan mahasiswa terhadap pelayanan yang diberikan oleh pihak fakultas.

2. Dapat mengetahui jenis pelayanan apa saja yang perlu diperbaiki, ditingkatkan dan dipertahankan.

3. Dapat diketahui jenis pelayanan apa saja yang benar-benar harus diprioritaskan untuk segera diperbaiki

B. Saran

Berdasarkan kesimpulan diatas dan agar dapat memaksimalkan peningkatan pelayanan dan peningkatan Aplikasi kedepan nanti nya maka dapat disarankan beberapa saran sebagai berikut :

1. Agar selalu dapat mengetahui indeks kepuasan mahasiswa terhadap pelayanan administrasi, maka hendaknya rutin melakukkan survei Tentang tingkat kepuasan mahasiswa pada fakultas Teknik minimal satu tahun sekali. 
Jurnal Pseudocode, Volume VI Nomor 2, September 2019, ISSN 2355-5920, e-ISSN 2655-1845 www.ejournal.unib.ac.id/index.php/pseudocode

2. Agar kedepannya dapat memaksimalkan penggunaan sistem survei IKM ini hendaknya Aplikasi penilaian dikembangkan secara online.

\section{DAFTAR PUSTAKA}

[1] Yoga Budi Bhakti, Eva Yuni Rahmawati. 2017. Indeks Kepuasan Mahasiswa Terhadap Pelayanan Program Studi Pendidikan Matematika. Penerbit Jurnal Formatif 7 : 272-285 ISSN 2088-351X

[2] Handayani, R, Yermias T. K., \& Ratminto. (2003). Analisis kepuasan pemakai terhadap pelayanan perpustakaan nasional provinsi daerah istimewa Yogyakarta. Sosiosains, vol 17, April 2003. Pasca Sarjana Fisipol UGM, Yogyakarta.

[3] I Wayan Suasnawa, I Nyoman Eddy Indrayana. 2017. Sistem Informasi Pengukuran Tingkat Kepuasan Mahasiswa Politeknik Negeri Bali. Penerbit Prosiding Sentrinov Tahun 2017 Volume 3 - ISSN: 2477 - 2097

[4] Tuti Sulastri, 2016. Analisis Kepuasan Mahasiswa Terhadap Kinerja Dosen Unisma. Penerbit Jurnal Jurnal Ilmiah Ekonomi Manajemen Dan Kewirausahaan “Optimal” Vol.10, No. 2 September 2016.

[5] Rendi .LS. 2014. Persepsi Mahasiswa Terhadap Pelayanan Administrasi Pegawai Biro Administrasi Akademik Dan Kemahasiswaan (Baak) Di Universitas Negeri Padang. Penerbit Jurnal Administrasi Pendidikan Volume 2 Nomor 1, Juni 2014

[6] Peraturan Menteri Pendayagunaan Aparatur Negara dan Birokrasi No. 14 Tahun 2017 tentang Pedoman Survei Indeks Kepuasan Masyarakat.

[7] Srinadi dan Nilakusmawati. 2008. "Faktor-Faktor Penentu Kepuasan Mahasiswa Terhadap Pelayanan Fakultas Sebagai Lembaga Pendidikan (Studi Kasus di FMIP, Universitas Udayana)" Jurnal Cakrawala Pendidikan. November. Th. XXVII 